\title{
La energía en la agenda externa argentina 2003-2015. El ascenso de Bolivia y Venezuela como reacción frente a la urgencia*
}

\author{
The Argentine External Agenda 2003-2015. \\ The rise of Bolivia and Venezuela as a \\ reaction to the emergency in energy issue
}

\author{
Natalia Ceppi** \\ María Elena Lorenzini***
}

\section{RESUMEN}

El presente artículo analiza las relaciones bilaterales de Argentina con Bolivia y Venezuela en materia energética en el período 2003-2015. Se sostiene como conjetura que el ascenso de ambos Estados en la agenda externa argentina es resultante de una reacción frente a la situación de urgencia en materia de energía que atravesaba el país, con el objetivo de garantizar el abastecimiento doméstico. El dinamismo de los vínculos estuvo marcado por el pragmatismo. Estos tuvieron similitudes, pero también claras diferencias. Más allá de las implicancias bilaterales, el capítulo

* El artículo es el resultado de los proyectos de investigación realizados por las autoras en su calidad de investigadores del Consejo Nacional de Investigaciones Científicas y Técnicas (CONICET). Este se inscribe el en el marco del Proyecto de Investigación POL/285 "Sudamérica en movimiento: (re) configuración de las agendas, análisis de los vínculos externos y desafíos en el Siglo XXI", aprobado por Resolución C.S. № 135/2019 de la Universidad Nacional de Rosario.

** Doctora en Relaciones Internacionales por la Universidad Nacional de Rosario. Profesora Titular de Derecho Consular y Diplomático en la Universidad Nacional de Rosario e Investigadora de CONICET.

** Doctora en Relaciones Internacionales por la Universidad Nacional de Rosario. Profesora Adjunta de Teoría de las Relaciones Internacionales en la Universidad Nacional de Rosario e Investigadora de CONICET. male_lorenzini@yahoo.com.ar. Recibido el 16 de enero de 2019. Aprobado el 1 de octubre de 2019. 
energético planteó el debate sobre los principales desafíos que Argentina debe afrontar en el corto y mediano plazo en el tratamiento de un sector estratégico para el crecimiento y el desarrollo.

Palabras clave: Argentina - Bolivia - Venezuela - agenda externa - energía.

\begin{abstract}
This article analyzes the bilateral relations Argentina-Bolivia and Argentina-Venezuela in energy issue area during 2003-2015. The main thesis uphold that the rise of both states in the argentine external agenda is the result of a reaction to the emergency in energy issue that the country was going through in order to guarantee domestic supply. Pragmatism marked the dynamic of both relations, which show similarities, but also differences. Beyond the bilateral implications, the energy chapter raised the debate on the main challenges that Argentina should face in the short and medium term when strategic sector were involved for growth and development matters.
\end{abstract}

Keywords: Argentina - Bolivia - Venezuela - foreign agenda energy.

\title{
INTRODUCCIÓN
}

La energía como tema de agenda de la política internacional, en general, y de la política exterior argentina (PEA), en particular, se configuró como prioridad durante la primera década del siglo xxi. Entre los factores que contribuyeron a su ascenso destacan el aumento de la demanda mundial, el crecimiento de los precios internacionales, la preocupación por el horizonte de agotamiento de los combustibles fósiles y los impactos que la compra-venta de este commodity tiene en las balanzas comerciales de los países según su condición — productores y exportadores, exportadores netos, productores e importadores, importadores netos- (García \& Garcés, 2012; Sabaíni, Jiménez \& Morán, 2015; Svampa, 2017; Gudynas, 2012; AIHE, 2011).

En 2010, las reservas internacionales de petróleo alcanzaron 1.466 millones de barriles, de los cuales el 23\% se localiza en Latinoamérica y el Caribe (García \& Garcés, 2012). Acompañando la tendencia internacional, los países de la región aumentaron su producción durante la última década, siendo Argentina, una de las excepciones que confirma la regla. 
Asimismo, se registró un crecimiento de las reservas internacionales en general; aumentos de la demanda y los precios. La demanda pasó de 69 millones de barriles diarios en 2000 a 85 millones en 2010 (García \& Garcés, 2012:17), mientras que el precio internacional del barril West Texas Intermediate (wTI) pasó de U\$S 30 en 2000 a U\$S 95 en 2009 (García \& Garcés, 2012: 16).El gas natural muestra un comportamiento similar al del petróleo en la demanda —en 2010 hubo un aumento del $40 \%$ en relación a 1990 - y los precios - U\$S 2,5 promedio el millón de BTU en 2000 a U\$\$ 5 promedio en 2010- (García \& Garcés, 2012). En la dimensión política, Sudamérica estuvo caracterizada por el ascenso de gobiernos progresistas, cuya "hegemonía política estuvo ligada al boom de los commodities", donde "las economías latinoamericanas fueron enormemente favorecidas por los altos precios internacionales de los productos primarios [...] hasta los años 2011-2013" (Svampa, 2017: 51). Así, progresismo y altos precios internacionales abrieron un nuevo capítulo en el debate sobre extractivismo/(neo) extractivismo ${ }^{1}$ rela-

1 Siguiendo a Svampa los rasgos del (neo) extractivismo son: "gran escala, orientación a la exportación, ocupación intensiva del territorio y acaparamiento de tierras, amplificación de impactos ambientales y sociosanitarios, preeminencia de grandes actores corporativos transnacionales y tendencia a la democracia de baja intensidad" (2017: 56), lo que muestra la coexistencia de la crítica al neoliberalismo con distintos arreglos con los sectores económicos vinculados al grancapital. cionados con la expansión de grandes proyectos en el área minera, hidrocarburífera y agrícola (Svampa, 2017: Svampa, 2013; Gudynas, 2012).

$\mathrm{Al}$ iniciarse la segunda década del siglo xxI, los académicos advierten 'un fin del ciclo progresista' (Svampa, 2017; Gudynas, 2012), un nuevo giro político a la derecha o el ascenso de una 'marea celeste' (Rovira, 2014; Vommaro, 2014; Burchardt, 2017; Lorenzini, 2017) como contracara de la marea rosa propuesta por Panizza (2006). Más allá de las diferencias y matices existentes, los estudios coinciden en el siguiente punto del diagnóstico de la situación regional: los gobiernos progresistas tuvieron buenas intenciones, expresadas en sus discursos, para desplazarse desde un modelo de desarrollo ortodoxo hacia otro neodesarrollista. No obstante, el elevado precio de las materias primas junto con la decisión política de sus líderes de impulsar esas exportaciones generó una re-primarización de sus economías. En consecuencia, las economías de los países no avanzaron sustantivamente en la industrialización y agregación de valor a su producción, sino que se concentraron en la exportación de materias primas. Por tanto, una vez finalizado el ciclo alcista de los precios, los países volvieron a experimentar los tradicionales problemas económicos —déficit comercial, déficit fiscal, estancamiento económico, endeudamiento, etc.- con las consecuencias políticas, económicas y sociales que ello trae 
aparejado (Svampa, 2013; Ffrench Davis, 2009; Ocampo, 2009; Rapetti \& Frenkel, 2009).

En ese contexto, Argentina comenzó a transitar una crisis energética (2004) de gran magnitud, y necesidades urgentes para garantizar el abastecimiento doméstico. Para sobrellevar la crisis, los gobiernos del Frente para la Victoria (FPV) recurrieron a Bolivia, un proveedor tradicional de gas, y a Venezuela, un actor que ascendió vertiginosamente como socio externo para colaborar en el suministro de fueloil y gasoil. En virtud de ello, nos preguntamos cómo influyeron las necesidades energéticas de Argentina en el ascenso de Bolivia y Venezuela como socios prioritarios de su agenda externa. La conjetura que guía este trabajo sostiene que el ascenso de Bolivia y Venezuela se comprende por el carácter de urgencia que implicó la crisis energética argentina y que se orientó a garantizar el abastecimiento doméstico. A ello se agrega el pragmatismo con el que los tres gobiernos decidieron abordar la cuestión: Argentina encontraba en ambos casos dos proveedores; Bolivia recuperaba su participación como exportador de gas, y Venezuela abría un mercado en el cual colocar, en principio, una parte de sus exportaciones.

El objetivo principal consiste en analizar los vínculos bilaterales de Argentina con Bolivia y Venezuela en materia de energía en el período 20032015. Así, examinamos la importancia de la energía en la agenda externa argentina y presentamos el panorama del sector energético argentino en el que se exhibe el cuadro general de la situación para comprender, a grandes rasgos, por qué se llegó a una crisis en 2004. Luego, analizamos su conexión con los vínculos bilaterales con Bolivia y Venezuela, prestando especial atención a los respectivos ascensos como socios prioritarios y a los resultados comerciales derivados del intercambio energético en cada uno de ellos - acuerdos firmados, volumen del intercambio de energía y dinero involucrado-. En tercer lugar, presentamos las reflexiones finales en las que analizamos los resultados de ambos pares de vínculos en materia de energía a la luz de las necesidades argentinas y sus impactos en la balanza comercial.

\section{La importancia de la energía en la política exterior}

¿Por qué es importante la energía? "En el plano político, el sector energético es objeto de preocupación respecto de situaciones de dependencia y desequilibrio de poderes, ya sea entre países (exportadores o importadores), entre grupos económicos, entre abastecedores y clientes, entre reguladores y regulados, o entre Estados y empresas importantes. En el plano macroeconómico, el sector energético tiene fuerte impacto sobre la balanza comercial y los ingresos fiscales, y también sobre los gastos y las inversiones públicas del Estado" (Zanoni, 2006: 178). A ello se suma el hecho que es un engranaje clave del aparato productivo en su 
conjunto, pues genera los insumos básicos para su funcionamiento (Zanoni, 2006). En la misma dirección, Linkohr afirma que "[1] as materias primas, sobre todo el petróleo y el gas, son una herramienta cómoda para hacer política",ya que "los ingresos provenientes de la extracción del petróleo y gas les otorgan a los países un mayor margen de acción, interno y externo" (Linkohr, 2006: 91). Desde esta perspectiva, siguiendo a Zanoni (2006) entendemos la política energética "como un conjunto de estrategias [...]" cuyos objetivos comprenden distintos campos: político, económico, social y de política exterior (PE), entre otros. En consecuencia, [1]a política energética adquiere un carácter multidimensional [...]"'(Zanoni, 2006: 179). Por tanto, los ingresos provenientes del comercio de energía funcionan como una herramienta de financiamiento del Estado y como un instrumento que puede ponerse al servicio de la PE. Un claro ejemplo de ello es Venezuela bajo el liderazgo de Chávez a partir de 2003/4, cuando se inició el ciclo alcista de los precios internacionales del petróleo. Esto nos permite comprender la relevancia de la energía y afirmar que ocupa un lugar vital en las agendas de los Estados en el plano doméstico y externo.

Esa lógica de razonamiento se enlaza con las ideas que el desempeño del sector energético es crucial para abastecer la demanda interna y que el desempeño del intercambio externo genera, cuando se exporta, divisas para el país, mientras que cuando se importa, provoca un drenaje de recursos que puede desequilibrar la balanza comercial.

\section{Panorama del sector energético argentino}

Una matriz energética constituye una representación cuantitativa de las fuentes de energía que dispone un país, en un período de tiempo determinado, para ser utilizadas en diferentes procesos productivos y satisfacer las necesidades socio-económicas de la población (Dagna, 2014). La matriz energética argentina exhibe una marcada concentración de combustibles fósiles. Para 2015, petróleo y gas natural representaban el $89 \%$ de la oferta de energía primaria, quedando en un lugar relegado las energías renovables como la hidráulica (4.8\%) o la eólica $(0.2 \%)$, entre otras (Ministerio de Energía y Minería de la República Argentina, 2015). Dicha concentración se mantuvo estable en términos porcentuales desde la década del setenta, aunque a partir del 2000, el gas natural lidera la oferta total de energía primaria a nivel nacional. A modo de ejemplo, en 1970 la proporción gas natural/ petróleo era $22 \%$ versus $68 \%$ y en 1990 el gas natural alcanzó el 39\% frente al $48 \%$ del petróleo. En cambio, en el período 2000-2015, la producción de gas natural se sostuvo alrededor del $52 \%$ 
- con variaciones de 1 o 2 puntos-y la del petróleo alrededor del $38 \%{ }^{2}$

La expansión del gas natural en detrimento del petróleo no fue un resultado fortuito. Desde la segunda mitad del siglo xx, el poder Ejecutivo impulsó - a través de una política de precios bajos- el uso del gas natural en los ámbitos residencial, industrial y en la generación de electricidad con miras a sustituir, paulatinamente, los combustibles líquidos como fueloil y kerosene, y avanzar en el autoabastecimiento petrolero (Pistonesi, 2001; Mansilla, 2007). Este proceso contó con el respaldo de dos acontecimientos: el descubrimiento, a fines de los setenta, de importantes reservas gasíferas en la cuenca neuquina ${ }^{3}$ — uno de los principales reservorios de hidrocarburos convencionales y no convencionales argentinos-y la importación de 4 a 6 millones de metros cúbicos diarios de gas natural $\left(\mathrm{MMm}^{3} / \mathrm{d}\right)$ desde Bolivia entre 1972 y 1999 (Pistonesi, 2001; Akly, 2007).

En 1990, como se observa en el Gráfico 1, Argentina era el segundo productor de gas natural de América del Sur y Central, después de Venezuela,

2 Datos obtenidos en base a los Balances Energéticos Nacionales (años varios) del Ministerio de Energía y Minería de la República Argentina. Información disponible enhttps://www.argentina.gob.ar/energia/ hidrocarburos/balances-energeticos-0

3 La cuenca neuquina comprende una zona geográfica de $124.000 \mathrm{~km}^{2}$ de gran potencial hidrocarburífero que abarca parte de las provincias de Neuquén, Mendoza, Río Negro y La Pampa. y contaba con el $13.4 \%$ del total de reservas gasíferas probadas de dicha subregión, cuya duración se estimaba en 25.2 años (Subsecretaría de Combustibles de Argentina, 1998: 19). Este contexto, conjuntamente con los envíos provenientes desde Bolivia, fue entendido por la administración de Carlos Menem (1989-1999) como una oportunidad político-económica para potenciar el dinamismo del sector mediante la exportación del hidrocarburo a Brasil y Chile. Ambos vecinos no solo tenían dificultades en términos de reservas y/o producción, sino que además — a diferencia de Argentinacarecían de obras de infraestructura conectadas con Bolivia.

El gobierno argentino se propuso consolidar al país como un proveedor gasífero de referencia regional, pero sin una participación activa del Estado. La industria energética nacional, representada en las empresas Yacimientos Petrolíferos Fiscales (YPF) - a cargo de la exploración y explotación- y Gas del Estado - que concentraba las actividades de transporte, distribución y comercialización- quedaron inmersas en el modelo de desarrollo ortodoxo implementado por el menemismo. ${ }^{4}$ Bajo esta lógica, el mercado adquirió un rol protagónico en la economía en su conjunto, privilegiando al sector privado, mientras que

4 Por modelo de desarrollo se entiende la "manera en la que se articulan las política y la economía, entre el Estado y el mercado, en un contexto histórico determinado" (Actis, Lorenzini \& Zelicovich, 2016: 16). 


\section{Gráfico I \\ Producción de gas natural en AC y del Sur (en Mtoe)}

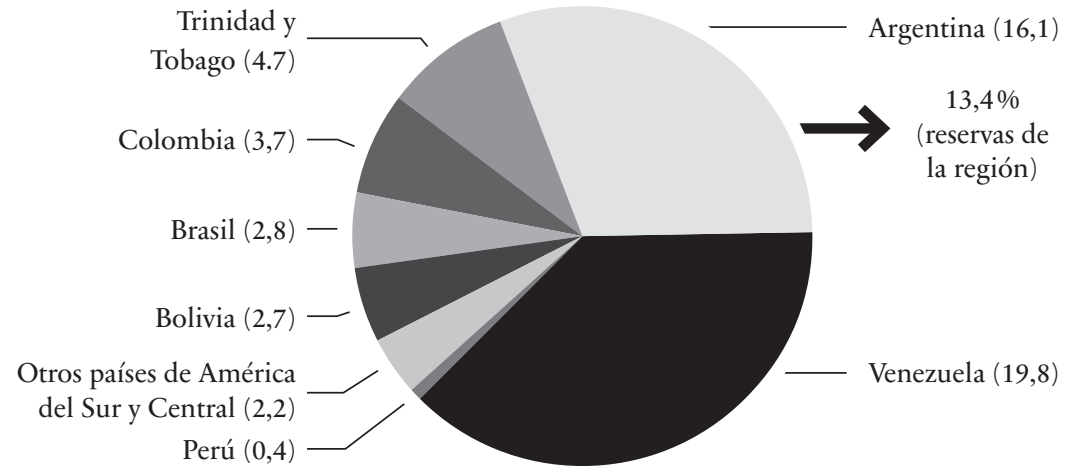

Fuente: Elaboración propia en base a los datos de BP (2016)

la presencia del Estado fue de 'carácter subsidiario, "especialmente como garante de las reglas de juego" (Actis, Lorenzini \& Zelicovich, 2016: 19-22).

El puntapié inicial fue la sanción de la Ley de Reforma del Estado (23.696) el 17 de agosto de 1989, que declaró, entre otras cuestiones, el estado de emergencia de la situación económico-financiera de las empresas estatales; sociedades del Estado y sociedades anónimas con participación estatal mayoritaria o de economía mixta (Ley 23.696, art. 1, 1989). Esta normativa habilitó y fomentó la privatización total, parcial o la liquidación de las empresas en las cuales el Estado figuraba como propietario. Amparándose en la necesidad de incrementar la productividad de los yacimientos y de reactivar aquellos que presentaban bajos niveles de actividad, la administración Menem decidió, en primer lugar, desregular, progresiva e integralmente, la actividad hidrocarburífera con el objetivo de reemplazar la intervención del Estado por mecanismos del libre juego de oferta y demanda (Decreto 1055, 1989). Dicho proceso implicó medidas como: llamados a licitaciones para explotación y comercialización de áreas hidrocarburíferas; libre disponibilidad de los hidrocarburos obtenidos por parte de los adjudicatarios; libre instalación de bocas de expendio; fijación de precios según condiciones de mercado; importación y exportación de hidrocarburos y derivados sin arancel, y la libre disponibilidad de las divisas obtenidas por los productores, 
con un límite del $70 \%$, entre las más relevantes. ${ }^{5}$

Una vez que el Estado fue apartado de las pautas que regían el comportamiento de la industria energética, YPF y Gas del Estado fueron privatizadas mediante un complejo esquema de venta de sus respectivos paquetes accionarios que, lejos de incentivar la competencia entre privados, resultó en un mercado de rasgos oligopólicos fuertemente concentrado (Pistonesi, 2001; Kozulj, 2004). En 1999, ypF fue adquirida en su totalidad por el grupo Repsol, denominándose Repsol-YPF. En tanto, Gas del Estado fue fragmentado en diez compañías que conformaron dos transportadoras - TGN en el norte y TGS en el sur- y ocho distribuidoras - Metropolitana, Buenos Aires Norte, Cuyana, del Centro, del Litoral, del Noroeste, Pampeana y del Sur-, las cuales obtuvieron una licencia por 35 años con la opción de 10 años más (Azpiazu \& Schorr, 2001). Si bien, en términos discursivos la división de Gas del Estado en distintas unidades de negocios se justificó para fomentar la competitividad empresarial, en la práctica, los dos subsistemas quedaron dominados por grupos económicos - ex contratistas de la compañía y de YPF-. El subsistema norte, controlado por Techint, Grupo Soldati y Grupo Macri, y el subsistema sur por

5 Consultar los Decretos 1055 (10/10/1989); 1212 (8/11/1989); 1589 (27/12/1989); 633 (12/04/1991). Información disponible en http://servicios.infoleg.gob.ar/ las empresas Total, Pérez Companc —adquirida por Petrobras en 2002y la financiera CEI Citicorp Holdings (Mansilla, 2007: 136).

A partir de la segunda mitad de los noventa, estas empresas, que también habían obtenido concesiones en las distribuidoras, fueron desprendiéndose de sus acciones, acrecentando la posición dominante de Repsol. Así, el conglomerado español participaba de forma directa o indirecta de las transportistas y/o distribuidoras de gas, controlando más del $50 \%$ de la totalidad del hidrocarburo ofertado al mercado doméstico y operaba la mayoría de los yacimientos gasíferos, en especial las cuencas neuquina y noroeste (Azpiazu \& Schorr, 2001).

La privatización del upstream y el downstream de la industria fue la materialización de las políticas neoliberales enmarcadas en el Consenso de Washington, con el objetivo de lograr la retirada del Estado como 'actor y regulador', transfiriendo estas facultades al sector transnacional. Como expresa Mansilla (2007: 124), dejar al rubro energético sin intervención estatal fue una decisión política que no consideró el valor estratégico que revisten las energías no renovables, porque las igualó a un producto comerciable más, sin considerar sus especificidades, entre ellas, que son bienes finitos y fundamentales para el desarrollo socio-económico de cualquier país. Es importante mencionar que el cambio radical que atravesó la industria energética argentina durante la década 
del noventa no constituyó un hecho aislado en la región. Con diferentes intensidades y características propias, los gobiernos de Bolivia y Perú también privatizaron sus respectivas empresas estatales a través de la modificación del entramado jurídico y la aplicación de incentivos fiscales para atraer inversión extranjera (Campodónico, 2004). En otras palabras, estos procesos quebraron el monopolio que, tradicionalmente, había tenido el Estado en el sector y, lo suplantaron por el mercado como agente rector de la política energética nacional.

La existencia de un Estado 'pasivo' en la cadena hidrocarburífera argentina, regulada por empresas transnacionales que, a su vez, actuaban de forma directa o con subsidiarias en el contexto contiguo; la laxitud del marco normativo y fiscal, y la disponibilidad de yacimientos gasíferos para desarrollar en términos comerciales, generaron las condiciones para 'constituir' un mercado energético regional interconectado. Esta afirmación se constata con los siguientes indicadores. En primer lugar, entre 1997 y 2002 se amplió la capacidad de transporte para la exportación del hidrocarburo hacia Chile, Brasil y Uruguay; países con dificultades en el autoabastecimiento del recurso. Entraron en operación 7 gasoductos hacia Chile - GasAndes (1997); Methanex (1997); Methanex Patagonia (1999); El Cóndor-Posesión (1999); NorAndino (1999); Atacama (1999); Pacífico (1999)—; 2 gasoductos hacia Uruguay —Petrouruguay (1998) y Cruz del Sur (2002) - y 1 gasoducto hacia Brasil — TGM (2000), (IAPG, 2007)—.Esta lógica no se replicó en el ámbito doméstico, ya que las compañías decidieron maximizar el uso de la infraestructura construida por Gas del Estado con inversiones a corto plazo y de fácil recuperación (Mansilla, 2007: 148). En segundo lugar, se destaca la intensidad de la actividad extractiva con el fin de satisfacer los requerimientos comprometidos para la exportación.

El Cuadro I da cuenta de la evolución de los volúmenes exportables y de la relación producción/reserva, la cual estipula la duración aproximada (en años) de las reservas probadas al ritmo de la producción vigente. Como observamos a continuación, los datos referidos a producción y exportación, tuvieron un marcado ascenso en el período. La producción, es decir, la explotación de los yacimientos, creció $36.4 \%$, pero las exportaciones lo hicieron exponencialmente (963.2\%), siendo Chile el principal importador. En cambio, el comportamiento general de las reservas fue decreciente (10.4\%), al igual que la ratio $\mathrm{P} / \mathrm{R}$, a pesar de un leve ascenso entre 1997 y 2001, situación que se vincula con la adquisición total de YPF por parte del grupo Repsol. Dicho declive se entiende por la profundización de la fase de explotación para alimentar la demanda externa y doméstica - que subió $21 \%$ entre los años señalados-y la falta de inversiones de los operadores transnacionales a nivel exploratorio para el descubrimiento de nuevas 
Cuadro I

Evolución del gas natural en Argentina (según indicadores)

\begin{tabular}{lllll}
\hline Datos & $\mathbf{1 9 9 7}$ & $\mathbf{1 9 9 9}$ & $\mathbf{2 0 0 1}$ & $\mathbf{2 0 0 3}$ \\
\hline Exportación & 670,74 & 3385,87 & 6051,47 & 6460,54 \\
Producción & 37.074 & 42.400 & 45.916 & 50.576 \\
Reservas & 683.796 & 748.133 & 763.526 & 612.496 \\
Ratio P/R & 18.44 & 17.64 & 16.63 & 12.11 \\
\hline
\end{tabular}

Fuente: Elaboración propia en base a los datos de la Secretaría de Energía de la República

Argentina. Anuario de Reservas (2004).

"Los volúmenes de exportación, producción y reservas están expresados en $\mathrm{MMm}^{3}$ la ratio $\mathrm{P} / \mathrm{R}$ en años.

reservas. Según datos del Ministerio de Energía y Minería, el promedio de pozos exploratorios perforados fue alrededor de 30 por año - a partir de 1999- ascendiendo a 52 en el 2000 para descender a 24 en $2003 .^{6}$

Ante la falta de capacidad de intervención del Estado en el sector energético argentino, "reservándose (...) únicamente la facultad o no de autorizar las exportaciones dada la prioridad fijada para el abastecimiento interno", las transnacionales contaron con 'luz verde' para desplegar una estrategia de inversión regional e internacional de maximización de la rentabilidad, sin considerar las implicancias de una producción creciente con reservas en baja (Kozulj, 2005: 18). La decisión de implementar una política energética regida de forma íntegra por las leyes

6 Argentina. Información disponible en http://www.energia.gob.ar/contenidos/ verpagina.php?idpagina $=3456$ de mercado eclosionaron tras la crisis socio-económica que atravesó Argentina en 2001 y su posterior salida del régimen de Convertibilidad en 2002 que, entre otros aspectos, al eliminar la paridad cambiaria de 1 peso argentino = 1 dólar estadounidense, pesificó los precios de los hidrocarburos en boca de pozo.

Con la llegada del gobierno de Néstor Kirchner (2003-2007), esta situación no pasó inadvertida debido a que el país comenzó a experimentar restricciones en la oferta doméstica. Si bien estas podrían ser —en parte- un modus operandi reactivo de las compañías para obtener mejoras en los precios o para impulsar las importaciones en U\$S, cabe subrayar que el desplazamiento del Estado de la industria estableció un punto de inflexión (Kozulj, 2005). De este modo, la disociación de la energía como bien económico y estratégico durante el menemismo $-\mathrm{y}$ luego con la Alianza- sentaron 
La energía en la agenda externa argentina 2003-2015. El ascenso de Bolivia y Venezuela como reacción frente a la urgencia

las bases de una situación energética crítica y con intereses estatales y empresariales involucrados. En este sentido, el kirchnerismo heredó un tema complejo de la agenda nacional con proyecciones en la PE, tal como se observa en los vínculos bilaterales que analizamos a continuación.

\section{El rol de la energía en la agenda externa Argentina: LoS víNCUlOS CON Bolivia Y VENEZUELA}

\section{Argentina y Bolivia, una 'vieja sociedad'en torno a la energía}

A partir de la llegada de la administración Kirchner, los vínculos con Bolivia comenzaron a exhibir un perfil renovado en el marco de la PEA, en especial en lo que respecta a la intensidad y el dinamismo de la relación. ${ }^{7}$ En este cometido fueron claves dos factores. Por un lado, la pertenencia del FPV y del Movimiento al Socialismo (MAS) - con la victoria de Evo Morales en 2005- al llamado 'ciclo progresista' y, por el otro, la existencia de temáticas de interés en la agenda compartida, entre ellas, los negocios energéticos. Ahora bien, el comercio de hidrocarburos, más precisamente de gas natural, no constituye per se una cuestión novedosa del presente siglo, sino que su emergencia data de décadas anteriores (Ceppi, 2012).

7 Con el gobierno de Néstor Kirchner, la relación argentino-boliviana comenzó a experimentar lo que Tini (2008) cataloga como 'un bilateralismo convergente.' Esta etapa se distancia del menemismo (19891999), la cual estuvo signada por un 'bilateralismo abandonado?
Los primeros pasos para la concreción de los negocios gasíferos entre los dos Estados se registraron en los años sesenta, cuando la empresa Gulf Oil ${ }^{8}$ - a cargo de la explotación de hidrocarburos en Bolivia-inició negociaciones con Gas del Estado para exportar gas natural hacia Argentina, con el propósito de monetizar las reservas ubicadas en los departamentos del sur del país (Fundación Jubileo, 2009: 12). En ese entonces, para el gobierno argentino de facto de Juan Carlos Onganía (1966-1970), la posibilidad de importar gas natural iba de la mano de los siguientes objetivos geopolítico-económicos: coadyuvar a la expansión de dicho recurso en la matriz energética nacional —en detrimento del petróleo-; alejar a Bolivia de la órbita de influencia brasileña y mitigar la infiltración de fuerzas de izquierda en el Ejecutivo boliviano (Escudé \& Cisneros, 2000). Así, la ecuación era simple.

8 La empresa estadounidense Gulf Oil Company llegó a Bolivia durante la administración de Víctor Paz Estenssoro (1952-1956), quien le concedió las áreas que hasta ese entonces pertenecían a ҮРғв y sobre las cuales había una vasta información geológica (Fundación Jubileo, 2009: 12). 
Las importaciones de gas natural serían el vehículo a través del cual Argentina se convertiría en el principal socio del Estado andino y este acercamiento obraría como mecanismo para contrarrestar, entre otras cuestiones, el avance de Brasil en el escenario subregional (Escudé \& Cisneros, 2000).

Luego de varias rondas de negociaciones, las empresas Yacimientos Petrolíferos Fiscales Bolivianos (YPFB), Gulf Oil y Gas del Estado suscribieron, el 23 de julio de 1968, un acuerdo de compra-venta por un período de 20 años, con un volumen de 4 MM$\mathrm{m}^{3} / \mathrm{d}$ durante los primeros 7 años $\mathrm{y}$ de $4.5 \mathrm{MMm}^{3} / \mathrm{d}$ desde el octavo año de contrato (Informe YPFB, s.f: 7). Este acuerdo no se puso en marcha de manera inmediata. Su inicio quedó supeditado a la tensión existente entre Gulf Oil y Bolivia, tras la decisión del General Ovando Candia de revertir las concesiones petrolíferas a favor de YPFB en octubre de 1969, dando origen a la segunda nacionalización de los hidrocarburos. ${ }^{9}$ Una vez resueltos los asuntos pendientes entre Үрғв y la

9 урғв fue creada el 21 de diciembre de 1936. Meses más tarde, la única compañía concesionaria de los campos hidrocarburíferos del país, Standard Oil, fue expulsada y se revirtieron todas sus propiedades a favor del Estado. Aquí se habla de la primera nacionalización de los hidrocarburos. En la presidencia de Víctor Paz Estenssoro, mediante la promulgación del Código Petrolero, se permitió nuevamente el ingreso de capitales privados a la industria energética boliviana. Información disponible en http://www.ypfb.gob.bo/es/informa cion-institucional/contexto-historico.html compañía estadounidense ${ }^{10}$ e inaugurado en 1972 el gasoducto binacional Santa Cruz-Yacuiba, conocido como YABOG, comenzaron las exportaciones de gas natural hacia Argentina (Informe YPFB, s.f: 7).

Este primer contrato energético fue modificado en varias oportunidades a través de ajustes de índole técnico o bien estableciendo prórrogas con la firma de otros acuerdos (Akly, 2007; Ceppi, 2012; Informe YPFB, s.f.). En los hechos, esto se plasmó en el mantenimiento de la compra-venta de gas natural hasta 1999, cuando Bolivia lanzó las exportaciones de dicho hidrocarburo a Brasil para abastecer a los principales centros industriales del país. Según datos de чрғв, en esos 27 años de negocios ininterrumpidos, Bolivia vendió a la Argentina 1,87 billones de pies cúbicos de gas natural por un valor de U\$S 4.562,35 millones (Informe YPFB, s.f: 8). ${ }^{11}$

10 Producto de la nacionalización, Gulf Oil aplicó un embargo que impedía la comercialización del petróleo al exterior y la continuidad de la construcción del gasoducto Bolivia-Argentina.

11 Para la Cámara Boliviana de Hidrocarburos y Energía (СBHE), otro momento importante en la historia energética compartida, se encuentra a partir del mes de septiembre de 1999 con la compañía privada argentina Pluspetrol. Esta intervino en la venta del hidrocarburo - calculada entre $1 \mathrm{MMm}^{3} / \mathrm{d}$ y 2 $\mathrm{MMm}^{3} / \mathrm{d}$ - por el gasoducto Bermejo-Aguas Blancas hasta septiembre de 2002. Información disponible en http://www.cbhe.org.bo/ index.php/nota-energetica/download/148_8cc565655bcb1e3e85145bdb5e359ca5 
La energía en la agenda externa argentina 2003-2015. El ascenso de Bolivia y Venezuela como reacción frente a la urgencia

\section{Gráfico II}

Exportaciones de gas natural boliviano hacia Argentina (primer contrato) (En $\mathrm{MMmm}^{3} / \mathrm{d}$ )

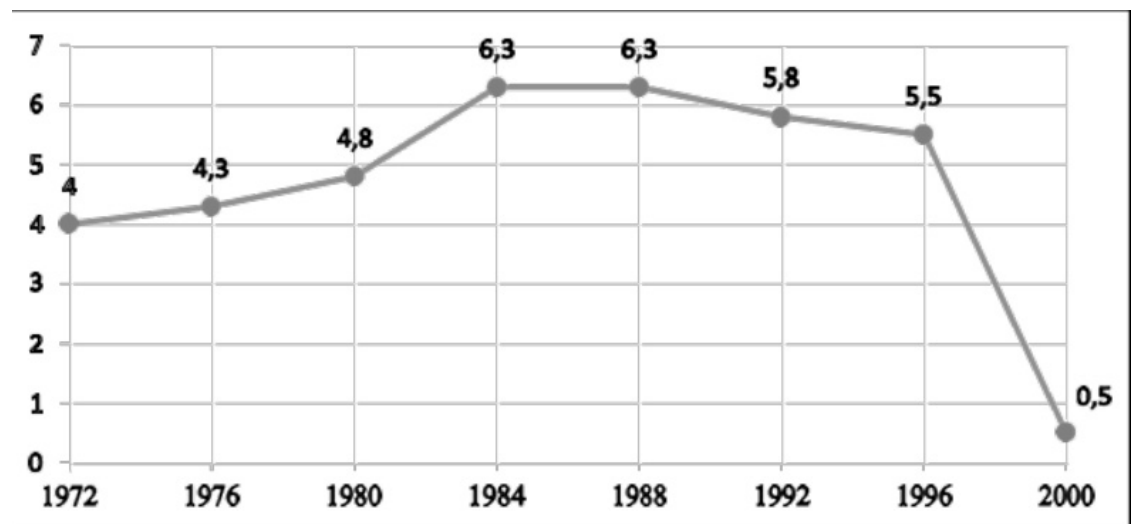

Fuente: Elaboración propia en base a Akly (2007) e Informe YPFB (s.f).

Los gobiernos del FPV y el Mas: un nuevo impulso en comercio energético

Los primeros años del presente siglo fueron testigos de un segundo capítulo en las relaciones argentino-bolivianas en materia de comercio gasífero. $\mathrm{Al}$ igual que en el pasado, cuando los dos Estados firmaron el primer contrato, las coyunturas nacionales eran claramente afines. Para Bolivia resultaba imperioso ampliar los volúmenes exportables de gas natural en un momento marcado por la crisis socio-política y económica. Debemos recordar que la 'Guerra del Gas', en octubre de 2003, fue el evento que determinó la renuncia de Gonzalo Sánchez de Lozada (2002-2003) a su segundo mandato y otorgó plena visibilidad a una de las épocas más convulsionadas que le tocó vivir al país interna y externamente (Zaratti Sacchetti \& Torres Orías, 2008). En este contexto, Carlos Mesa Gisbert (2003-2005) - vicepresidente de Sánchez de Lozada - tenía la compleja tarea de trabajar en múltiples frentes abiertos: aprovechar la abundancia de reservas de gas natural boliviano y consolidar al Estado como un proveedor por excelencia en la región; aprobar una nueva normativa de hidrocarburos-demandada por la sociedad en su conjunto-, y evitar las posibles represalias de los inversores energéticos transnacionales. Como expresan Zaratti Sacchetti \& Torres Orías (2008: 127), "la temática de los hidrocarburos marcó profundamente 
la gestión del Presidente Carlos Mesa Gisbert (...), desde el origen de su mandato, pasando por éxitos y fracasos, hasta causar el desenlace de su período presidencial”.

Por su parte, durante los primeros meses de 2004, el gobierno de Néstor Kirchner también tuvo a la energía como una cuestión de impacto en la agenda nacional. Sin embargo, el foco del debate estaba puesto en cómo afrontar un panorama energético con graves dificultades. Como indicamos anteriormente, las desinteligencias del pasado generaron las condiciones para que el país experimentara grandes deficiencias en materia de abastecimiento energético a nivel residencial, comercial e industrial. Esta situación, a su vez, repercutió de forma negativa en la PE, más precisamente en los vínculos con Chile. Debido a los problemas para sostener la demanda doméstica, la administración del FPV decidió racionalizar - y en ocasiones interrumpir - sin comunicación previa, las exportaciones de gas natural a su vecino, las cuales estaban reguladas por el Protocolo Gasífero de 1995. La unilateralidad de la medida derivó en la 'Crisis del Gas', puesto que la falta de comunicación argentina tomó por sorpresa al gobierno de Ricardo Lagos (2000-2006), teniendo en cuenta que Chile había estructurado su matriz energética en la década del noventa en base al suministro gasífero argentino (Lorenzini, 2011). En otras palabras, la decisión intempestiva del Ejecutivo argentino de suspender los envíos de gas hacia Chile, comprometió el abastecimiento de las centrales de producción y las posibilidades de acceso del recurso por parte de los habitantes. La 'Crisis del Gas' representó “el conflicto más severo que experimentó la relación bilateral (...) desde 1990", a pesar de no haber contaminado otras áreas de cuestiones de la agenda compartida (Lorenzini, 2011: 235).

Frente a una situación crítica a nivel doméstico y externo, el gobierno argentino no dudó en reflotar la compra-venta de gas natural boliviano. Dicho tema no solo era considerado un pilar fundamental en la construcción del vínculo con Bolivia, sino que además estaban dadas las condiciones para embarcarse nuevamente en negocios energéticos conjuntos.

En el marco de la Declaración de Buenos Aires, el 21 de abril de 2004, Mesa Gisbert y Kirchner reanudaron la compra-venta de gas natural por un volumen máximo de importación/exportación de $4 \mathrm{MMm}^{3} / \mathrm{d}$ por un período de 6 meses, con la posibilidad de renovar y/o ampliar las cantidades establecidas (Convenio Temporario de Venta de Gas Natural entre la República Argentina y la República de Bolivia, 2004). De la letra de este convenio se desprenden dos elementos que dan cuenta de cuán importante era para ambos países activar el comercio de energía. El primero radica en el ofrecimiento de Bolivia de establecer un 'precio solidario' de venta - en ese entonces U\$S 0.98 por millón de BTU-, entendiéndose como una expresión 
de cooperación bilateral por los años de continuidad en la comercialización hidrocarburífera. El segundo lo encontramos en la aceptación del gobierno argentino de no exportar a terceros países el energético boliviano; cuestión no menor, si tenemos en cuenta las decisiones que generaron la 'Crisis del Gas' con Chile (Ceppi, 2010).

El Convenio de 2004 fue renovado y ampliado, a petición de la administración Kirchner, hasta el 31 de diciembre de 2006, fijando un volumen máximo de $7.7 \mathrm{MMm}^{3} / \mathrm{d}$ (tercera adenda al Convenio Temporario de Venta de Gas Natural entre la República Argentina y la República de Bolivia, 2005). Sin embargo, con el ascenso de Evo Morales a la Presidencia de Bolivia, en enero de 2006 - quien manifestó su voluntad de tener una "estrecha correlación y coordinación” con el gobierno de Kirchner y mejorar la venta de gas hacia Argentina (Febbro, 2005)—, se modificaron las condiciones acordadas durante la gestión Mesa Gisbert.

El comercio gasífero Argentina-Bolivia quedó supeditado a una medida que fue anticipada en plena campaña electoral del mas: la nacionalización de ypFB y la renegociación de los contratos de explotación hidrocarburífera. Esta decisión fue puesta en marcha a través del Decreto Héroes del Chaco (28.701), el 1o de mayo de 2006, anunciado por Evo Morales en el campo San Alberto (Departamento de Tarija). En una fecha cuyo lado simbólico tuvo su máxima expresión - el Decreto fue lanzado en el Día Internacional del Trabajador, como resultado de una lucha histórica y con la presencia de las Fuerzas Armadas como muestra de poder soberano-, el Presidente boliviano presentó la nacionalización como un freno a la 'subasta' de los recursos naturales del país. Con este Decreto, el mas dispuso: i) la plena recuperación estatal en toda la cadena de la producción hidrocarburífera; ii) la nacionalización de las acciones necesarias (mínimo 51\%) de las empresas Chaco, Andina, Transredes, Petrobras Bolivia Refinación y la Compañía Logística de Hidrocarburos de Bolivia a favor de YPFB; iii) la adecuación a dicha medida por parte de las empresas transnacionales que explotaban los campos bolivianos, mediante la firma de nuevos acuerdos en un plazo máximo de 180 días (Decreto 28.701,2006). ${ }^{12}$

En un primer momento, podríamos pensar que como el gobierno argentino carecía de una compañía estatal (y/o con capitales mayoritariamente nacionales) operando en la industria energética boliviana - a diferencia de Brasil, por ejemplo- la necesidad de sentarse con premura

12 En términos de valor de la producción, cabe aclarar que este Decreto sólo dispuso un adicional del $32 \%$ a favor de YPFB - a cargo de los operadores- solo durante el período de transición y para los campos cuya producción certificada promedio de gas natural al 2005 haya sido superior a los 100 millones de pies cúbicos diarios. De este modo, el valor de producción se distribuía en: $18 \%$ en regalías, $32 \%$ en Impuesto Directo a los Hidrocarburos (IDH), $32 \%$ adicional a favor de чрғв у $18 \%$ para las compañías (Decreto 28.701, 2006). 
en la mesa de negociación parecía un tanto exacerbada. No obstante, la existencia de grandes dificultades para alimentar la totalidad de la demanda doméstica con producción propia - $\mathrm{y}$ manteniendo precios razonables-, explicó la urgencia del comportamiento del gobierno argentino. Luego de varios meses de encuentros entre funcionarios de primer nivel, el 19 de octubre de 2006, los presidentes de ENARSA empresa argentina de mayoría estatal, creada en 2004 por el Ejecutivo- e YPFB suscribieron un contrato de compra-venta de gas natural por un período de 20 años, con volúmenes crecientes hasta alcanzar un máximo de 27.7 $\mathrm{MMm}^{3} / \mathrm{d}$ (Contrato ENARSA-YPFB, 2006). Para concretar las metas de envíos, paralelamente se reactivó el proyecto de construcción del gasoducto del nordeste argentino (GNEA), lanzado inicialmente en 2003 (Ceppi, 2010). Sin embargo, el Fpv no logró culminarlo a lo largo de sus tres mandatos. La suscripción del contrato ENARSA-YPғв de 2006 reafirmó la direccionalidad que había tomado la relación bilateral dos años antes, cuando los escenarios domésticos de Argentina y Bolivia impulsaron la compra-venta de energía en la agenda conjunta. La centralidad que tuvo esta issue area en el vínculo bilateral durante el mandato de Néstor Kirchner se hizo extensiva a las dos administraciones de Cristina Fernández (2007-2015).

Como se observa en el Cuadro II, las importaciones gasíferas se mantuvieron en volúmenes estables y/o ascendentes, con algunos pequeños descensos puntuales. A lo largo de ese período, ambos Estados acordaron, debido a factores coyunturales propios, establecer modificaciones de índole técnico, tales como reajustes en las cantidades pautadas según los meses del año y en los plazos de entrega, la inauguración en 2011 de un gasoducto - Juana Azurduy, para su posterior conexión al GNEA-y la incorporación de una garantía de pago a favor de YPFB, entre otras.

El sostenimiento sin interrupciones de las importaciones de gas natural boliviano a partir de la eclosión de la crisis energética en 2004, incluso con la decisión de Morales de establecer cambios en las reglas de juego contractuales, producto de la nacionalización, fue determinante en el fortalecimiento de Bolivia en el marco de la PEA en general y en los vínculos sudamericanos en particular. Desde la firma del convenio entre Kirchner y Mesa Gisbert, Argentina se convirtió en el segundo socio comercial de Bolivia después de Brasil, mientras que Bolivia pasó a ser el único proveedor de gas natural de la región durante los gobiernos del FPV.

Sin quitarle mérito a la reactivación de la compra de gas en el proceso de recomposición de la agenda bilateral, subrayamos que las importaciones del hidrocarburo reflejan las desinteligencias del Ejecutivo argentino para gestionar un sector vital como el energético, en especial cuando el gas natural representa más del $50 \%$ de la matriz. 
La energía en la agenda externa argentina 2003-2015. El ascenso de Bolivia y Venezuela como reacción frente a la urgencia

\section{Cuadro II}

Importaciones de gas natural boliviano (gobiernos del FPv)

\begin{tabular}{rrr|rcr}
\hline Año & Kg. & Valor CIF & Año & Kg. & \multicolumn{1}{c}{ Valor CIF } \\
\hline 2004 & 799.278 .000 & 68.443 .691 & 2010 & 1.586 .826 .986 & 297.610 .583 \\
\hline 2005 & 1.559 .2598 .928 & 186.570 .724 & 2011 & 2.165 .650 .943 & 564.542 .508 \\
\hline 2006 & 1.602 .009 .032 & 243.302 .430 & 2012 & 3.103 .306 .180 & 1.104 .450 .801 \\
\hline 2007 & 1.495 .342 .280 & 139.288 .703 & 2013 & 4.781 .641 .000 & 2.531 .078 .711 \\
2008 & 826.524 .392 & 76.717 .824 & 2014 & 4.491 .143 .624 & 2.234 .024 .070 \\
\hline 2009 & 1.528 .630 .782 & 158.180 .691 & 2015 & 4.476 .136 .511 & 1.367 .747 .3961 \\
\hline
\end{tabular}

Fuente: Elaboración propia en base a los datos de INDEC (Argentina). Valor CIF expresados en millones de U\$S.

Como plantea Bravo (2015), durante el kirchnerismo se pusieron en marcha un conjunto de acciones con diferentes grados de impacto e importancia- en el marco de la política energética nacional, destacándose, entre otras, los planes de Energía Total, los programas de Petróleo Plus, Refinación Plus y Gas Plus, la expropiación del grupo Repsol-YPF (2012), el Decreto 929 (2013), los programas de uso racional de energía, la Ley de Hidrocarburos 27007 (2014). A pesar de ello, la dependencia de las importaciones de gas natural boliviano para abastecer parte del consumo doméstico, la tendencia de reservas en baja, la falta de incremento en la producción y los desequilibrios de la balanza energética comercial, ${ }^{13}$ han sido indicadores de una política energética sin rumbo, cortoplacista y carente de una mirada estratégica.

\section{Argentina y Venezuela, nuevos socios en el inicio del siglo XXI}

Los vínculos argentino-venezolanos tienen una larga historia

13 Según los datos del Instituto Argentino del Petróleo y del Gas (IAPG), entre los años 2006-2015, las reservas gasíferas descendieron alrededor del $27,2 \%$. En cuanto a la producción de gas natural, en el período bajo estudio, el nivel máximo fue en 2004 con 52.385 millones de $\mathrm{m}^{3}$. A partir de entonces, esta fue perdiendo dinamismo, al punto que en 2015 los valores se registraron en 42.896 millones de $\mathrm{m}^{3}$. Con respecto a la balanza energética, solo en el caso del gas natural, de la información disponible del IAPG se desprende una diferencia a favor de las importaciones de 55.434 .823 miles de $\mathrm{m} 3$ entre 2006 y 2015. Estadísticas interactivas en http://www.iapg.org.ar/estadisticasnew/ 
diplomática que se remonta a su conformación como Estados-nación independientes. Se trata de dos Estados que interactuaron de manera predominantemente cooperativa (Seitz, 2012; López Belsué, 2009).

Durante los noventa, estas relaciones bilaterales ocuparon un lugar no prioritario en sus respectivas agendas externas, aunque ambos gobiernos coincidieron en adoptar los lineamientos neoliberales en sus políticas económicas y exteriores. La actividad bilateral se estructuró en torno a la percepción mutua del 'otro' como mercado potencial para colocar productos y capitales -Argentina invirtió volúmenes significativos hasta $1998^{14}$ dentro de un esquema que priorizó la dimensión comercial. No obstante, el intercambio comercial argentino-venezolano fue reducido. Venezuela ocupó el puesto 12 como destino de exportaciones argentinas y el puesto 42 como origen de importaciones (Centro de Economía Internacional, 2009). Debemos destacar que el rubro energía no formó parte del intercambio comercial durante esa década, pero

14 Equivalente al 17,7\% de la IED emitida por el país (Kosacoff, 1999: 8). La fecha de corte responde a la incertidumbre en el clima de negocios que generó la posibilidad de triunfo de Hugo Chávez en las elecciones presidenciales de 1998. En la fase siguiente, Chávez decidió expropiar aquellas empresas definidas como 'estratégicas.' Entre ellas estuvo Sidor, perteneciente al Grupo Techint. se transformó en un issue clave en la década siguiente.

Desde 2003, las relaciones argentino-venezolanas se convirtieron súbitamente en prioritarias para los respectivos esquemas de PE. El punto de inflexión fue la Reunión de Cancilleres del 31 de julio 2003, oportunidad en la que estos expresaron la voluntad de profundizar el vínculo en múltiples issue areas - cooperación y comercio de energía, alimentos, maquinarias, ciencia y tecnología, etc.En 2004 se firmó el Convenio Integral de Cooperación (CIC) y se constituyó en el principal instrumento para regular y gestionar, formalmente, el vínculo. Desde entonces, su trayectoria se caracterizó por la intensidad y velocidad con la que se desarrolló hasta 2007 —reuniones regulares, crecimiento del comercio bilateral, proyectos de cooperación-. Sin embargo, se sucedieron un conjunto de hechos desafortunados - valija gate, nacionalización de Sidor, sospechas de pago de coimas junto al peculiar mecanismo que regulaba el comercio de energíaque, ante la crítica de diversos actores y sectores, condujeron a la decisión política de solapar el perfil público de la relación y reducir la visibilidad de los encuentros entre funcionarios. Pese a ello, los gobiernos mantuvieron el vínculo en un nivel prioritario, tal como lo demuestra la continuidad del intercambio comercial, la firma de nuevos acuerdos y adendas que se sumaron a los ya existentes. Finalmente, 
cabe señalar que el ritmo de firma de acuerdos se mantuvo hasta mayo de 2013. Según los datos de la Biblioteca Digital de Tratados del Ministerio de Relaciones Exteriores y Culto de Argentina, el último acuerdo entre ambos países se firmó el 8 de mayo de 2013. Desde nuestra perspectiva, este dato significa que la dinámica de la relación se habría modificado luego del fallecimiento de Chávez.

\section{El CAPÍTULO ‘ENERGÍA’ EN LA AGENDA ARGENTINO-VENEZOLANA}

$\mathrm{Al}$ igual que el vínculo bilateral, el capítulo energético se inició con la firma del cic (2004). Allí se estableció un mecanismo de consulta permanente entre los Ministerios de Energía y Minas (Venezuela) y el Ministerio de Planificación Federal (Argentina) para la compra-venta de fueloil y gasoil basado en intereses mutuos: la crisis energética iniciada en 2004 en Argentina hizo que el país no pudiera satisfacer con recursos propios la demanda doméstica y Venezuela, tradicionalmente, abasteció su demanda de alimentos y maquinaria vía importaciones. En este caso, encontraba un nuevo socio que tenía el potencial para diversificar sus proveedores tradicionales -Colombia y EE.UU., entre otros-.

El artículo vi del cic establecía que Venezuela se comprometía a proveer a Argentina fueloil y gasoil según las condiciones acordadas en el Anexo I. ${ }^{15}$ Esto implicaba que PDvsa vendería a CAMMESA hasta 8 millones de barriles de fueloil y hasta 1 millón de barriles de gasoil entre mayo-octubre de 2004.

El artículo vir establecía que la Corporación Estatal CASA, el Ministerio de Agricultura y Tierras y la Corporación Venezolana de Guyana (CGV), gestionarían la compra de alimentos, productos agrícolas e insumos para la industria petrolera. Allí se explicita que el intercambio de energía por alimentos se llevaría a cabo siguiendo los principios de reciprocidad, equilibrio y precios internacionales competitivos (CIC, 2004).

15 Dicho Anexo fue modificado en 18 oportunidades entre 2004-2013. La mayoría de los Addendums versaron sobre la compra de energía: cambiaron las instituciones responsables del comercio - el Addendum 11/2008 incorporó a ENARSA y, el 12/2008, a ENARSA PDV-; revisaron plazos y condiciones de pago - Addendum 3/2004, 4/2005, 11/2008,17/2012 y 18/2013 - y ampliaron volúmenes de compra —el Addendum 11/2008 lo elevó a $10 \mathrm{mbd}$ de fueloil y 2,30 mbd de gasoil—; el 12/2008 amplió a 2,96 mbd gasoil. 
Ahora bien, los pagos por el comercio de los productos mencionados se efectuaron a través de un fideicomiso. Desde septiembre de 2012, el rol de fiduciario le correspondió a Nación Fideicomisos Sociedad Anónima. ${ }^{16}$ Cabe preguntarnos, entonces, cómo funcionaba este mecanismo singular. Las compras de hidrocarburos líquidos que CAMmesa y enArsa realizaban a PDVSA, eran pagadas por una transferencia de fondos que las empresas argentinas hacían a favor de la venezolana y que depositaban en el fideicomiso. Luego, esos mismos recursos serían utilizados por Venezuela para efectuar los pagos a las empresas exportadoras argentinas. La constitución del fideicomiso suponía: i) un mecanismo comercial alternativo en el que se intercambiaban alimentos y maquinarias argentinas por fueloil y gasoil venezolano, adquiriendo el

16 Originalmente los fiduciarios eran el Banco de Desarrollo Social de Venezuela y el Banco de Inversión y Comercio Exterior de la Argentina. Desde la firma del Addendum $\mathrm{N}^{\circ} 17$ del CIC el fideicomiso BANDES-BICE fue reemplazado por Nación Fideicomisos S.A. El nuevo fiduciario "emitirá Valores Representativos de Deuda por cada título transferido al fideicomiso (...) destinados a efectuar los pagos a las empresas argentinas por la adquisición de bienes y/o prestación de servicios y/o ejecución de obras, por exportación (...) a Venezuela (...); adquisición de bienes y/o activos, aportes o participaciones societarias y/o prestación de servicios y/o ejecución de obras en la República Argentina; y/o adquisición de todos aquellos bienes, servicios u obras que se incluyan eventualmente en el futuro en ese Convenio" (Addendum No 17, 2012: 17). dinero un valor más bien simbólico, y ii) un canal de financiamiento para Argentina durante el largo período en el que careció de acceso al mercado internacional de capitales. La peculiaridad del instrumento hacía que el comercio no fuera percibido como un negocio tradicional y adquiriera un 'halo' de 'solidaridad' que se ajustaba a las ideas e intereses que estructuraban el vínculo Buenos Aires-Caracas (Lorenzini, 2014).

A lo largo de estos últimos años, mucho se especuló sobre las compras de energía y trascendieron diversas versiones. Una afirma que el fueloil y el gasoil importado de Venezuela superaban el contenido máximo de azufre permitido por la legislación argentina. Otra sostiene que los combustibles no son originarios de Venezuela y que pDvsa los compraba a otros proveedores - Brasil y México son dos de los países mencionados - triangulándolos hacia Argentina y cobrando una comisión, lo que implica un aumento del costo de importación (iProfesional, 2016). Una tercera muestra una inconsistencia de datos: mientras $\mathrm{Ar}-$ gentina continuó exportando fueloil entre 2004 y 2015 (INDEC), también lo importaba de Venezuela. ¿Qué sentido tenía comprar un producto que Argentina producía y cuyo excedente exportaba a mercados exigentes? ¿Dónde se supone que radicaba el negocio? En la diferencia de dinero entre exportaciones ғов - Free on Board-e importaciones $\mathrm{CIF}$ - Cost, Insurance and Freight-. Dicha maniobra encarecía 


\section{Cuadro III}

Importaciones fueloil y gasoil 'Origen indeterminado (continente)' montos CIF en millones de U\$S

\begin{tabular}{|ll|}
\hline 2005 & 54.985 .089 \\
\hline 2006 & 381.202 .866 \\
\hline 2007 & 757.339 .657 \\
\hline 2008 & 1.475 .303 .222 \\
\hline 2009 & 317.820 .363 \\
\hline 2010 & 386.288 .811 \\
\hline 2011 & 1.027 .863 .204 \\
\hline 2012 & sin datos \\
\hline 2013 & sin datos \\
\hline 2014 & sin datos \\
\hline 2015 & sin datos \\
\hline Total & 4.400.803.212 \\
\hline
\end{tabular}

Fuente: Elaboración propia en función datos INDEC

el costo del combustible importado $y$, en consecuencia, los gobiernos del FPV habrían defraudado al fisco por cifras millonarias ${ }^{17}$ (Ex Secretarios de Energía, 2014).

Una cuarta, advierte que desde 2005 - momento en que el InDEC dejó de publicar los datos de importación de fueloil y gasoil provenientes de Venezuela - se observó un crecimiento exponencial del rubro 'origen

17 El fuel se exportó a U\$S 355 por tonelada mientras que se lo importó a U\$S 392 por tn. Eso implicó un quebranto económico por U\$S 36.344.800 sólo en 2007 y según cifras INDEC (Ex Secretarios de Energía, 2014: 56). indeterminado continente.' Se supone que a través de esa maniobra se 'escondían' las importaciones provenientes de Venezuela (Fernández Blanco, 2012; Ex Secretarios de Energía, 2014).

Estos rumores se alimentaron por la falta de transparencia de la información ya que es conocido que Argentina tuvo un blackout estadístico entre 2005-2016. De acuerdo con los datos oficiales del INDEC, el único registro de Venezuela como origen de importaciones de gasoil es 2004, cuyo valor fue de U\$S 8.422.880 millones.

Para estimar el valor aproximado de las importaciones de fueloil y gasoil de Venezuela entre 2005-2015, realizamos 
el siguiente cálculo, basado en un conjunto de fuentes diversas: se tomaron los datos de importaciones de gasoil y fueloil de 'origen indeterminado (continente)' del INDEC. ${ }^{18} \mathrm{~A}$ estos valores se le descontaron los pagos realizados a través de la emisión de instrumentos financieros - pagarés, letras del Tesoro-, los valores de la deuda reconocida oficialmente por el Decreto 1839/2010 y las Resoluciones 412/2010, 121/2010, 290/2012 y 75/2012 de la Secretaría de Hacienda y de Finanzas, respectivamente. Esto nos permitió obtener un valor aproximado del total de importaciones de energía de Argentina a Venezuela entre 2004-2015.

El Decreto 1829/2010 reconocía la existencia de una deuda pendiente de CAMMESA Y ENARSA CON PDVSA derivadas de las compras de energía realizadas en 2007 y 2008. El 15 de mayo 2009, las tres empresas celebraron un Contrato de Refinanciamiento para la cancelación de deuda con la emisión de 24 pagarés. En esa dirección, la Resolución Conjunta 412/2010 y 121/2010 de la Secretaría de Hacienda y de Finanzas reconoció una deuda de enaRsa y CAMmesa con pDVSa de U\$S1.264.832.345, 07 millones. Ambas Resoluciones dispusieron la emisión de 24 pagarés para la cancelación total de deuda. De acuerdo con el análisis de la información oficial de carácter público, Argentina tuvo voluntad de pago aunque se emitieron 6 pagarés menos de lo establecido en las Resoluciones y que el valor conocido de los mismos resulta inferior a la deuda total. De ello inferimos que quedó un saldo pendiente de pago por U\$S 445.964.575 para 2012.

Ahora bien, en octubre de 2012 las Secretarías de Hacienda y Finanzas emitieron las Resoluciones Conjuntas 290/12 y 75/2012, en las que se dispuso la emisión de Letras del Tesoro Nacional para afrontar otro tramo de la deuda argentina por importación de energía venezolana. Estas reconocían una deuda con PDVSA de CAMMESA por U\$S 1.378.357.753 y de ENARSA por U\$S 21.642.247.

18 Cálculo fundado a partir de la información hallada en Ex Secretarios de Energía (2014). 
La energía en la agenda externa argentina 2003-2015. El ascenso de Bolivia y Venezuela como reacción frente a la urgencia

\section{Cuadro IV}

Pagarés ENARSA (millones U\$S)

\begin{tabular}{|cc|}
\hline Monto & Vencimiento \\
\hline 31.198 .665 & $15 / 02 / 2011$ \\
\hline 31.198 .665 & $15 / 05 / 2011$ \\
\hline 8.783 .705 & $15 / 05 / 2011$ \\
\hline 31.198 .665 & $15 / 08 / 2011$ \\
\hline 31.198 .665 & $15 / 11 / 2011$ \\
\hline $\mathbf{6 . 6 6 8 . 1 1 2}$ & $15 / 11 / 2011$ \\
\hline 73.955 .515 & $15 / 02 / 2012$ \\
\hline 73.955 .515 & $15 / 05 / 2012$ \\
\hline 3.814 .841 & $15 / 05 / 2012$ \\
\hline 291.972 .348 & Total \\
\hline
\end{tabular}

\section{Cuadro V}

Pagarés CAMMESA (millones U\$S)

\begin{tabular}{|cc|}
\hline Monto & Vencimiento \\
\hline 56.301 .335 & $15 / 05 / 2011$ \\
\hline 56.301 .335 & $15 / 05 / 2011$ \\
\hline 15.851 .137 & $15 / 05 / 2011$ \\
\hline 56.301 .335 & $15 / 08 / 2011$ \\
\hline 56.301 .335 & $15 / 11 / 2011$ \\
\hline 12.033 .341 & $15 / 11 / 2011$ \\
\hline 133.460 .657 & $15 / 02 / 2012$ \\
\hline 133.460 .657 & $15-$ feb \\
\hline $\mathbf{6 . 8 8 4 . 2 9 0}$ & $15 / 05 / 2012$ \\
\hline 526.895 .422 & Total \\
\hline
\end{tabular}

Fuente: Elaboración propia a partir datos Decreto 1829/2010. 
Tal como observamos en el Cuadro VI, entre 2012 y 2015 el INDEC no registró importaciones de gasoil y fueloil de "origen indeterminado continente". Esta situación coincide con el desembarco en 2013 de Axel Kicillof en el Ministerio de Economía, quien se hizo cargo de la energía, antes gestionada por Planificación Federal. El nuevo ministro puso fin a las importaciones de fueloil a PDVSa y acordó un plan de pago en 22 cuotas mensuales para saldar la deuda de U\$S 1.088 millones correspondiente a los embarques

\section{Cuadro VI}

Pagos documentados en millones de U\$S realizados por Argentina

\begin{tabular}{|l|l|}
\hline Pagarés ENARSA (2010) & 291.972 .348 \\
\hline Pagarés CAMMESA (2010) & 526.895 .422 \\
\hline Letras ENARSA (2012) & 21.642 .247 \\
\hline Letras CAMMESA (2012) & 1.378 .357 .753 \\
\hline Plan pago (2013) & 1.088 .000 .000 \\
\hline Total pagos & 3.306 .867 .770 \\
\hline $\begin{array}{l}\text { Saldo pendiente deuda } \\
\text { reconocida (2015) }\end{array}$ & 247.000 .000 \\
\hline
\end{tabular}

Fuente: Elaboración propia en función datos Decreto 1839/2010, Resoluciones 412/2010 y 121/2010; 290/2012 y 75/2012 y iProfesional (2016).

recibidos entre 2010 y 2011. Posteriormente, no se encontró documentación oficial ni periodística que haya registrado pagos. De hecho, al 10 de diciembre 2015, el presidente Macri reconoció una deuda en el fideicomiso de U\$S 247 millones la cual fue cancelada en 5 cuotas de U\$S 49,5 millones cada una hasta diciembre 2016. Después de un año de gestión, la administración de CAMBIEMOS logró saldar la deuda por la compra de energía con Venezuela. En función de los datos presentados, afirmamos que la compra de combustibles fue real y que, pese a la opacidad del fideicomiso, se realizaron pagos parciales.

Si quisiéramos saber qué porcentaje de fueloil y gasoil importado como "indeterminado continente" fue comprado a Venezuela, podemos realizar el siguiente cálculo: Total Importaciones origen indeterminado (continente) - Pagos realizados (pagarés, Letras y Plan Pago) + Importaciones a Venezuela en 2004 (registro INDEC) + Saldo pendiente emisión pagarés + Deuda Pendiente Fideicomiso (diciembre 2015). 
La energía en la agenda externa argentina 2003-2015. El ascenso de Bolivia y Venezuela como reacción frente a la urgencia

\section{Cuadro VII \\ Valor aproximado en millones de U\$S de importaciones fueloil y gasoil a Venezuela}

\begin{tabular}{|l|l|}
\hline $\begin{array}{l}\text { 4.400.803.212 } \\
8.422 .880\end{array}$ & Total M origen indeterminado \\
3.306 .867 .770 & Importaciones Vz 2004 \\
445.964 .575 & Pagos realizados \\
247.000 .000 & Deuda diciembre 2015 \\
\hline
\end{tabular}

Elaboración propia en función datos Decreto 1839/2010, Resoluciones 412/2010 y 121/2010; 290/2012 y 75/2012 y iProfesional (2016).

Ese total aproximado de compras a Venezuela representó alrededor del $60 \%$ de las importaciones totales de fueloil y gasoil de origen indeterminado continente entre 2005-2015.

\section{REFLEXIONES FinALES}

El tratamiento de la energía como tema de agenda regional y de PE en materia de desafíos y oportunidades-adquirió en el presente siglo un perfil ascendente, producto de factores diversos de órdenes sistémicos y propios de las realidades domésticas estatales. En este contexto, Argentina no fue la excepción. Para la administración Kirchner, la cuestión energética cobró prioridad y fue un desafío en el marco de las políticas públicas debido a las dificultades surgidas en 2004 para sostener el abastecimiento energético con producción nacional. Sin lugar a dudas, ello guarda relación con el modo a través del cual los gobiernos de turno gestionaron la política energética. La falta de control estatal sobre la desinversión de las empresas transnacionales que operaban en el sector para el fortalecimiento de las actividades exploratorias, el establecimiento de precios inferiores a los del mercado y el subsidio al consumo sin aumento de tarifas, fueron algunas de las medidas que generaron una situación energética crítica y compleja. Sus repercusiones se dieron en el ámbito doméstico y alcanzaron a un conjunto de vínculos bilaterales en particular y a la PE en general.

En cuanto a las relaciones bilaterales, el problema energético ocasionó, por un lado, una crisis en el mejor vínculo de Argentina con su vecino 
Chile. Por el otro, el ascenso vertiginoso de Bolivia y Venezuela como socios prioritarios en virtud de su condición de proveedores de hidrocarburos y derivados. En otras palabras, fue la urgencia - plasmada en la crisis energética argentina- la que les otorgó un nuevo impulso a sendas vinculaciones.

En el caso de Bolivia, la necesidad de abastecimiento de gas natural significó una oportunidad para reflotar una sociedad comercial cuyos antecedentes se remontan a la década del sesenta. Mientras que para el gobierno argentino, la disponibilidad de las reservas gasíferas bolivianas mitigó la incertidumbre en materia de provisión; para Bolivia, la reanudación de las exportaciones energéticas constituyó una excelente oportunidad comercial debido a la dependencia hidrocarburífera de la economía y al momento crítico en el cual se concretó el acuerdo. Durante las administraciones del FPv, la relación bilateral en torno a la energía transcurrió sin mayores sobresaltos. A excepción de algunos entredichos en torno a las definiciones de las condiciones de compra-venta, luego del decreto de nacionalización en 2006 y de la falta de construcción del GNEA, entre otros, no se registraron dificultades en la gestión de la relación. Prueba de ello es que en reiteradas oportunidades, Argentina y Bolivia realizaron ciertos cambios y ajustes de índole contractual con el objetivo de mantenerse en calidad de importador y exportador, respectivamente.
En el caso de Venezuela, se produjo un ascenso vertiginoso de un socio no tradicional en el esquema de PEA. Como señalamos, la firma del cic y sus respectivos addendums - la mayoría, amplió los volúmenes de fueloil y gasoil- marcó un punto de inflexión en esta relación. Venezuela se convirtió en un proveedor de energía para Argentina en un contexto de necesidades de suministro crecientes. Este vínculo se asentó en una complementariedad selectiva de intereses y en la sintonía política de sus máximos líderes. Una de sus peculiaridades consistió en la utilización del Fideicomiso - mecanismo poco convencional y transparente - para administrar los intercambios comerciales. Ello despertó sospechas de corrupción y suspicacias en torno a la gestión de la relación, pues el INDEC ocultó datos relativos al origen y volumen de las importaciones energéticas. De acuerdo con los ex Secretarios de Energía de Argentina, ello se observó en el salto cuantitativo que experimentó el rubro 'origen indeterminado continente' para las compras de fuel y gasoil.

Una de las principales diferencias entre los dos vínculos analizados estriba en la transparencia con la que se gestionó la compra de energía. Argentina-Bolivia celebraron diversos acuerdos cuya información completa fue de carácter público. Si se los consultaba, se encontraban tanto los volúmenes de gas natural que Argentina importaba y el precio pagado. Mientras que 
el intercambio de hidrocarburos líquidos entre Argentina-Venezuela aún sigue siendo desconocido, haciendo la gestión de este último desprolija y opaca. En este trabajo, hicimos una reconstrucción de datos con el objetivo de conocer, de manera aproximada, el tamaño del negocio energético argentino-venezolano. De allí se infiere que Argentina gastó mucho dinero en este rubro. Ello se observa en el valor de los instrumentos financieros emitidos por el gobierno para saldar, parcialmente y con años de atraso, las compras de combustibles. En la misma dirección, algunos especialistas afirman que el negocio energético argentino-venezolano tuvo como saldo una defraudación al Estado pues la Casa Rosada nunca pudo explicar la simultaneidad de las exportaciones de fueloil y las importaciones del mismo producto proveniente de Venezuela. De hecho, el rubro energético de la balanza comercial argentina explica el abultado déficit comercial que se acumuló entre 2003-2015 - en 2003 representó el $4 \%$ del total de las importaciones y en 2015, el 19\%-.

Por último, en lo que respecta a la PE sobresalen acontecimientos tales como la pérdida paulatina del rol de Argentina como proveedor energético tradicional; el aumento desmedido de las importaciones de gas natural, gasoil, fueloil y petróleo, y el deterioro de la balanza comercial tras la pérdida de divisas vía reducción de las exportaciones y el aumento de las importaciones. Si a esto le sumamos el relanzamiento en múltiples oportunidades del GNEA — sin llegar a su concreción-y la ausencia de claridad y transparencia en los negocios energéticos argentino-venezolanos, entendemos que, en el período en estudio, prevalecieron en la política energética decisiones de carácter reactivo, sin previsibilidad sobre el futuro que no consideraron la magnitud de las repercusiones. Esta situación, además de reflejar la falta de valoración estratégica que marcó el accionar de los gobiernos argentinos en el tratamiento de la energía, también deja planteado un conjunto de desafíos, cuya superación requiere una diagramación seria con miras al mediano y largo plazo, más que decisiones gubernamentales de índole coyuntural.

\section{Bibliografía}

AA.VV. Ex Secretarios de Energía (2014) La Política Energética como política de Estado. Consensos para una política energética. Buenos Aires: Instituto Argentino de la Energía General Mosconi.
Actis, E.; Lorenzini, M.E. \& Zelicovich, J. (2016). "Modelo de desarrollo y estrategia de inserción: claves para la interpretación de su relación", en Busso, A. (Coord.), Modelos de Desarrollo e 
Inserción Internacional. Aportes para el análisis de la politica exterior argentina desde la redemocratización 1983-2011. Rosario: UNR Editora, pp. 15-30.

Akly, Y. (2007). "Un nuevo marco para los Contratos de Operación en Bolivia" [versión electrónica] Petrotecnia, junio, pp. 62-68. Recuperado el 15 de abril de 2015 de http://www.petrotecnia.com. ar/junio07.htm

Alconada Mon, H. (2016). El gobierno cerró un polémico fideicomiso con Venezuela. La Nación, 24 de agosto. Recuperado el 28 de agosto de 2016 de https://www. lanacion.com.ar/1930949-el-gobiernocerro-un-polemico-fideicomiso-convenezuela

Argentina. Centro de Economía Internacional (2009). Argentina, principales indicadores económicos 1990-2009. Recuperado el 15 de julio de 2015 de http:// cei.mrecic.gov.ar/html/mercosur.htm.

Argentina. Energía Argentina Sociedad Anónima (2006). Contrato de compra venta de gas natural Energía Argentina S.A.y Yacimientos Petrolíferos Fiscales Bolivianos Recuperado el 5 de mayo de 2013 de http://www.enarsa.com.ar/ images/pdf/contrato_compra_venta_ enarsa_ypfb.pdf

Argentina. Información Legislativa (1989). Decreto 1055 Hidrocarburos, 10 de octubre. Recuperado el 23 de mayo de 2017 de http://servicios.infoleg.gob.ar/ infolegInternet/anexos/0-4999/1840/nor ma.htm

Argentina. Información Legislativa (1989). Ley 23.696 Reforma del Estado, 17 de agosto. Recuperado el 23 de mayo de 2017 de http://servicios.infoleg.gob.
ar/infolegInternet/anexos/0-4999/98/ norma.htm

Argentina. Ministerio de Energía y Minería (s.f). Balance Energético Nacional.Año 2015. Revisión 2. Recuperado el 9 de agosto de 2017 de http://datos.minem. gob.ar/dataset/balances-energeticos

Argentina. Ministerio de Planificación Federal, Inversión Pública y Servicios (2010). Decreto 1839/2010. Recuperado el 11 de diciembre de 2010 de http://servi cios.infoleg.gob.ar/infolegInternet/ane xos/175000- 179999/177594/norma.htm.

Argentina. Ministerio de Relaciones Exteriores y Culto (2004). Convenio Integral de Cooperación entre la República Argentina y la República Bolivariana de Venezuela. Recuperado el 14 de marzo de 2018 de trata dos.mrecic.gov.ar/tratado_archivo. php?tratados_id=16333\&tipo=1\&id.

Argentina. Ministerio de Relaciones Exteriores y Culto (2005). Tercera Adenda al Convenio Temporario de venta de gas natural entre la República Argentina y la República de Bolivia. Recuperado el 17 de mayo de 2018 de http:// tratados.mrecic.gov.ar/tratado_archivo. php?tratados_id=11556\&tipo=18id=8821 \&caso $=$ pdf

Argentina. Ministerio de Relaciones Exteriores y Culto (2004). Convenio Temporario de venta de gas natural entre la República Argentina y la República de Bolivia. Recuperado el 17 de mayo de 2018 de http://tratados.mrecic.gov.ar/tra tado_archivo.php?tratados_id=16337\& tipo=1\&id=7306 \&caso=pdf

Argentina. Secretaría de Hacienda y Secretaría de Finanzas (2012). Resolución 
La energía en la agenda externa argentina 2003-2015. El ascenso de Bolivia y Venezuela como reacción frente a la urgencia

Conjunta 290/2012 y 75/2012. Recuperado el 3 de marzo de 2013 de http://servi cios.infoleg.gob.ar/infolegInternet/ane xos/215000- 219999/216841/norma.htm.

Argentina. Secretaría de Hacienda y Secretaría de Finanzas (2010). Resolución Conjunta 412/2010 y 121/2010. Recuperado el 15 de enero de 2011 de http://servi cios.infoleg.gob.ar/infolegInternet/ane xos/175000-179999/177594/norma.htm.

Argentina. Subsecretaría de Combustibles. Secretaría de Energía (1998). Boletín Anual de Reservas de Hidrocarburos 1998, Buenos Aires.

Azpiazu, D. \& Schorr, M. (2001).Desempeño reciente y estructura del mercado gasífero argentino: asimetrías tarifarias, ganancias extraordinarias y concentración del capital. Buenos Aires: FLACSO.

Bolivia. Fundación Jubileo (2009). Nacionalizaciones de los hidrocarburos en Bolivia. Recuperado el 13 de abril de 2018 de http://www.jubileobolivia.org. bo/publicaciones/revistas-especializa das/item/131-nacionalizaciones-de-hi drocarburos-en-bolivia.html

Bolivia. Gaceta Oficial del Estado Plurinacional de Bolivia (2006). Decreto 28.701. Recuperado el 19 de mayo de 2018 de http://www.gacetaoficialdebo livia.gob.bo/app/webroot/index.php/ normas/buscar

Bolivia. YPFB (s.f). Informe de la Vicepresidencia de Negociaciones Internacionales y Contratos. Recuperado el 15 de mayo de 2018 de http://www. ypfb.gob.bo/informe_mensual_activi dades/252946.pdf

BP (2016). Statistical Review of World Energy, june. Recuperado el 13 de mayo de
2015 de https://www.bp.com/content/ dam/bp/pdf/energy-economics/statisti cal-review-2016/bp-statistical-review-ofworld-energy-2016-full-report.pdf

Bravo, V. (2015). Análisis de la Ley 27007, llamada de hidrocarburos, y de la política hidrocarburífera del período 2003 a 2014. Documento de Trabajo, Bariloche: Fundación Bariloche-CONICET.

Bresser Pereira, L.C. (2007). "Estado y mercado en el nuevo desarrollismo". Nueva Sociedad, № 210, pp. 110-125.

Burchardt, H. (2017). "La crisis actual de América Latina: causas y soluciones”. Nueva Sociedad, № 267, pp. 114-128.

Campodónico, H. (2004). Reformas e inversión en la industria de hidrocarburos en América Latina. Santiago de Chile: CEPAL, Serie Recursos Naturales e Infraestructura.

Ceppi, N. (2012). Cooperación y discordia por el uso y aprovechamiento de recursos naturales. La incidencia de lo doméstico en las relaciones trilaterales de Argentina, Bolivia y Paraguay (19942008) y en las bilaterales de Argentina y Bolivia (2003-2007). (Tesis Doctotal en Relaciones Internacionales) Universidad Nacional de Rosario.

Ceppi, N. (2010). "La temática energética en las relaciones entre Argentina y Bolivia. Acuerdos y contrariedades por el gas natural”. Foro Internacional, Vol. L, №1, enero-marzo, pp. 5-34.

Dagna, C. (2014). Matriz energética argentina: ¿qué se debe hacer? Observatorio Petrolero Sur. Recuperado el 11 de noviembre de 2017 de http://www.opsur. org.ar/blog/2014/12/08/matriz-energeti ca-argentina-que-se- debe-hacer/ 
Ecuador. Asociación de la Industria Hidrocarburífera del Ecuador (2011). El petróleo en cifras. Recuperado el 15 de abril de 2018 de http://biblioteca.olade.org/ opac-tmpl/Documentos/cg00065.pdf.

Escudé, C. \& Cisneros, A. (2000). Historia de las Relaciones Exteriores Argentinas, Buenos Aires: CARI-CEPE. Recuperado el 13 de abril de 2018 de http://www. argentina-rree.com/14/14-016.htm.

Febbro, E. (2005). Lula, Kirchner y Chávez, los elegidos. Buenos Aires, Página 12, 20 de diciembre: Buenos Aires.

Fernández Blanco, P. (2012). Dejan de publicar datos clave sobre el costo de la importación de energía. La Nación. Recuperado el 5 de octubre de 2012 de https://www.lanacion.com.ar/1514545dejan-de-publicar-datos-clave-sobreel-costo-de-la-importacion-de-energia.

Ffrench-Davis, R. (2009). "El impacto de la crisis global en América Latina”. Nueva Sociedad, N²24, pp. 67-85.

Gudynas, E. (2012). "Estado compensador y nuevos extractivismos. Las ambivalencias del progresismo latinoamericano". Nueva Sociedad, N²37, pp. 128-146.

Honty, G. (2006). "Energía en Sudamérica: una interconexión que no integra”.Nueva Sociedad, №206, pp. 119-135.

IProfesional (2016). Mauricio Macri heredó una deuda de US\$250 millones con Venezuela. Recuperado el 16 de marzo de 2016 de http://www.iprofe sional.com/comex/229241-deuda-ve nezuela-combustible-Mauricio-Ma cri-heredo-una-deuda-de-us250-mi llones-con-Venezuela.
Kosakoff, B. (1999). Las multinacionales argentinas, una nueva ola en los noventa. Documento de Trabajo CEPAL, № 83. Kozulj, R. (2005). Crisis de la industria del gas natural en Argentina. Santiago de Chile: CEPAL, Serie Recursos Naturales e Infraestructura.

Kozulj, R. (2004). La industria del gas natural en América del Sur: situación y posibilidades de la integración de mercados. Santiago de Chile: CEPAL, Serie Recursos Naturales e Infraestructura.

Linkohr, R.(2006). "La política energética latinoamericana: entre el Estado y el mercado", Nueva Sociedad, ${ }^{\circ}$ 204. pp. 90-103.

López Belzué, M. (2009). La gestión Kirchner y los Tratados bilaterales. Centro de Estudios para la Nueva Mayoría. Buenos Aires: CEUN.

Lorenzini, M.E. (2017). ¿Baja la marea rosa, sube la marea celeste? El Centro Relativo del Sistema Político Regional y la Agenda Sudamericana. Paper presentado en I Seminário Internacional das Relações Econômicas e Políticas no Atlântico Sul. Departamento de Relações Internacionais da Pontifícia Universidade Católica de Minas Gerais, 27 y 28 de marzo. Belo Horizonte.

Lorenzini, M.E. (2015). "Las relaciones Argentina-Venezuela 2010-2013: despejando los intereses en la trastienda ideológica", en Bologna, A. (Comp.) La política exterior de Cristina Fernández al finalizar su mandato. Rosario: CERIR-UNR, pp. 257-282.

Lorenzini, M.E. (2011). Política exterior, alianzas estratégicas y energía en América 
La energía en la agenda externa argentina 2003-2015. El ascenso de Bolivia y Venezuela como reacción frente a la urgencia

Latina. Las relaciones argentino-chilenas bajo la lupa. Rosario: Homo Sapiens.

Mansilla, D. (2007). Hidrocarburos y politica energética. De la importancia estratégica al valor económico: Desregulación y Privatización de los hidrocarburos en Argentina. Buenos Aires: Ediciones del CCC.

Ocampo,J.A. (2009). "La crisis económica global: impactos e implicaciones para América Latina”. Nueva Sociedad, № 224 , pp. 48-66.

Panizza, F. (2006). “La Marea Rosa”. Correo Americano, $\mathrm{N}^{\circ}$ 8, pp. 5-24.

Pistonesi, H. (2001). Desempeño de las industrias de electricidad y gas natural después de las reformas: el caso de Argentina. Santiago de Chile: ILPES-CEPAL, Serie Gestión Pública.

Rapetti, M. \& Frenkel, R. (2009). “La crisis mundial desde los países en desarrollo: algunas reflexiones". Nueva Sociedad, $\mathrm{N}^{\circ}$ 224, pp. 86-103.

Rovira, C. (2014). "La derecha en América Latina y su lucha contra la adversidad”. Nueva Sociedad, No 254, pp. 34-45.

Seitz, A.M. (2012). Argentina y Venezuela las extraordinarias claves de su segundo reencuentro en el siglo $\mathrm{xx}$ (1940-49).
Proyecciones presentes y futuras. Buenos Aires: FEPAI.

Svampa, M. (2017). “Cuatro claves para leer América Latina”.Nueva Sociedad, $\mathrm{N}^{\circ} 268$, pp. 50-64.

Svampa, M. (2014). “Consenso de las commodities y lenguajes de valoración en América Latina”.Nueva Sociedad, $\mathrm{N}^{\circ} 244$, pp. 30-46.

Tini, M.N. (2008). "La distancia sobre la cercanía: la política exterior argentina hacia Bolivia y Paraguay" [versión electrónica]. Revista Relaciones Internacionales, Vol.17, № 34, pp.197-221. Recuperado el 13 de junio de 2015 de https:// revistas.unlp.edu.ar/RRII-IRI/article/ view/1355/1319

Vommaro, G. (2014). "Meterse en política: la construcción política del PRO y la renovación de la centro-derecha argentina”.Nueva Sociedad, N²54, pp. 57-72. Zanoni,J.R. (2006). ¿Qué pueden hacer las políticas energéticas por la integración?”. Nueva Sociedad, N²04, pp. 176-185.

Zaratti Sacchetti, F. y Torres Orías, G. (2008). "Política de Hidrocarburos", en Mesa Gisbert, C. (Coord.), Un gobierno de ciudadanos. La Paz: Plural Editores/Fundación Comunidad, pp.126-150. 
